\title{
Association between Lifestyle and Severity of Menopausal Symptoms in Postmenopausal Women
}

\author{
Nooshin Yoshany ${ }^{1}$, Seyed Saeed Mazloomy Mahmoodabad ${ }^{2}$, Narjes Bahri ${ }^{3}$, Mahdiyeh Khaleghi Moori ${ }^{4}$, \\ Fahad Hanna ${ }^{5}$
}

${ }^{1}$ PhD Student in Health Education \& Health Promotion, Social Determinants of Health Research Center, School of Public Health, Shahid Sadoughi University of Medical Sciences, Yazd, IRAN

${ }^{2} \mathrm{PhD}$ in Health Education \& Health Promotion, Social Determinants of Health Research Center, School of Public Health, Shahid Sadoughi University of Medical Sciences, Yazd, IRAN

${ }^{3}$ Assistant Professor in Reproductive Health, Department of Midwifery, Faculty of Medicine, Social Development \& Health Promotion Research Center, Gonabad University of University of Medical Sciences, Gonabad, IRAN

${ }^{4}$ B.S student in Public Health, school of public health, Shahid Sadoughi university of medical sciences, Yazd, IRAN

${ }^{5} \mathrm{PhD}$ in Public Health, Faculty of Health, Torrens University Australia, Melbourne, AUSTRALIA

${ }^{\star}$ Corresponding Author: mazloomy.mm@gmail.com

Citation: Yoshany N, Mazloomy Mahmoodabad SS, Bahri N, Moori MK, Hanna F. Association between Lifestyle and Severity of Menopausal Symptoms in Postmenopausal Women. Electron J Gen Med. 2020;17(5):em222. https://doi.org/10.29333/ejgm/7885

ARTICLE INFO

Received: 17 Jan. 2020

Accepted: 5 Feb. 2020

\begin{abstract}
Objective: Menopause is a physiological occurrence characterized by a series of bothersome symptoms. Given that lifestyle affects people's health in general and many menopausal symptoms are influenced by changes in lifestyle, this study aimed to determine the relationship between lifestyle and severity of menopausal symptoms in women referred to health centers in Yazd city.

Method: This cross-sectional study was performed using stratified random sampling where 343 postmenopausal women who had experienced natural menopause for 1-5 years, and did not have any chronic or debilitating disease were selected. The study was conducted in 2017 in Yazd city, Iran. The data collection tools were Walker's Health Promoting Lifestyle Profile II (HPLP2) and Menopause Rating Scale (MRS) questionnaires. A multiple hierarchical linear regression was used to investigate the association between lifestyle and severity of menopausal symptoms.

Results: The total mean \pm (SD) score of menopausal symptoms severity and women's lifestyle were $10.21 \pm 6.55$ and $126.44 \pm 79.27$, respectively. The results of multiple hierarchical linear regression showed a significantly negative association between lifestyle score and the mean score of menopausal symptoms severity in all three models ( $P$-value $<0.001)$

Conclusion: Our study concluded that healthier lifestyle reduces the severity of menopausal symptoms. These findings warrant that policy makers in the design of postmenopausal care plans and programs ought to pay special attention to the role of healthy lifestyles, including physical activity and healthy diet in enhancing menopausal symptoms. By preventing aggravation of menopausal symptoms; it is possible to economize on referrals to physicians and medicinal and therapeutic costs. Longitudinal and intervention studies with larger sample size may be required to confirm these findings.
\end{abstract}

Keywords: menopausal symptoms, postmenopausal, severity, life style

\section{INTRODUCTION}

Menopause is a physiological phenomenon that is caused by the pause of the activity of the ovaries followed by complete menstrual cessation, as defined by the World Health Organization (1). Although menopause is considered a physiological phenomenon, due to the severity of symptoms and the global trend of aging populations, women's health at the age of menopause is very important $(2,3)$. According to the Iranian Statistics Center in 2011, there were $10.74 \%$ women aged 40-60 years old in Iran (4). Although menopause is a natural physiological manifestation that affect all women, in some cases the severity of the symptoms can affect the person's daily activities and communications (5-7). A study by
Olanjobo and colleagues on postmenopausal women found that menopausal symptoms had a negative effect on occupational responsibilities (8). Several factors affect the severity and manifestation of menopausal symptoms, including inappropriate diet, stress and lack of physical activity $(9,10)$. Today, in order to minimize the problems of menopause, various strategies such as regular physical activity programs and proper diet are recommended (11).

Lifestyle is a part of life that is actually being realized and encompasses a full range of activities that people do in daily life. Healthy lifestyle includes proper nutrition, physical activity, avoiding drug use, protection against accidents, timely diagnosis of disease symptoms in the physical dimension, emotional control, and adaptation to the 
environment (12). Nowadays, it is believed that $70 \%$ of the diseases are associated with the individual's lifestyle (13). In many studies, the role of lifestyle in modifying of symptoms and disease progression has been proven. For example Ghezelbash et al., in a comprehensive literature review; found that people with high blood pressure could greatly control their disease through lifestyle changes (14). Another study by Babaei et al. concluded that educational intervention was effective in promoting physical activity, improving weight control and nutrition, and improving mental health in patients with hypertension (15). Furthermore, Ghorbani et al. found, in their study, that healthy lifestyle reduces vasomotor symptoms in postmenopausal women (16) while a study on 400 postmenopausal women showed Healthy lifestyle improves quality of sleep in postmenopausal women (17). The study by Tartibian that looked at the role of physical activity revealed that regular aerobic exercise program reduces serum FSH levels in postmenopausal women and vasomotor symptoms (18), Moreover, Blümel et al. reported high prevalence of sedentary lifestyle in a sample of middle-aged Latin American women that was associated with more severe menopausal symptoms and obesity (19). Limited studies $(19,20)$ have examined the severity of all menopausal symptoms and their relationship with lifestyle; therefore, the present study was conducted to investigate the relationship between lifestyle practices and severity of menopausal symptoms in postmenopausal women in Iran.

\section{MATERIALS AND METHODS}

This study was cross-sectional in design. Sample size was calculated using related studies in the field $(16,17)$. Considering the error level of $0.05 \%$ and the power of $80 \%$ and according to the correlation coefficient of 0.158 reported from the relationship between lifestyle and menopausal complications, the sample size required for the present study was 312 with a final number of 343 subjects when considering an extra $10 \%$ to allow for dropout. The inclusion criteria included: passing at least 1 year and maximum 5 years of menopause, no early menopause, minimum level of education at junior-high school level, absence of a chronic and/or debilitating disease, Iranian nationality, having no history of hysterectomy and oophorectomy, willingness to participate in the study, absence of unpleasant and stressful incidents in the last 6 months, and no particular diet plan or regular drug use.

The demographic data were collected using a demographic checklist including 10 questions about age, education, income, occupation, duration of menopause, housing status, number of children, age of marriage, number of pregnancies, and age at menopause. The Walker's Health Promoting Lifestyle Profile II (HPLP2) questionnaire used in this study consisted of 52 questions including 6 components. The scoring of the HPLP2 questionnaire is based on a 4-point scale; each score is as follows: never: 1 , sometimes: 2 , often: 3 , normally: 4 ; adding up to a highest score of 208 and lowest score of52.Lin et al., showed that Cronbach's a for this questionnaire was 0.96 and that for each subscale ranged from .77 to .87 . Also, its reliability and validity on Iranian women has been published previously (21). Menopause severity was assessed by the Menopause Rating Scale (MRS) questionnaire. The MRS evaluate11 menopausal symptoms including: hot flushes and sweating, heart discomfort, sleep problems, depressive mood, irritability, anxiety, physical and mental exhaustion, sexual problems, bladder problems, vaginal dryness and joint and muscular discomfort. These questions were measured based on a 5-point Likert scale. The lower the overall score of the MRS, the lower the severity of the experienced symptoms. The validity and reliability of this international tool for measuring the severity of menopausal symptoms has been confirmed in previous clinical and epidemiological study (17).

The data were analyzed using Statistical Package for the Social Sciences (SPSS) software version 18. The descriptive analyses mean \pm (standard deviations) for continuous and number (percent) for categorical variables were used to assess the data. In bivariate analysis; Pearson correlation coefficient, t-test and one-way ANOVA were applied to specify the association of the studied variables with MRS.

Three hierarchical multiple linear regression models were conducted to examine adjusted association of lifestyle and MRS. Based on relevant literature and using p-value cut-off point of $<0.02$, the variables were entered into the regression models. In the univariate model lifestyle was entered (unadjusted model). In the multivariate model, variables such as age, job, and ownership of house, education level, and income were also entered. In the third model, in addition to the variables entered in previous model, the variables of menopausal duration, marriage age, menopause age, number of deliveries, and the number of children entered the model. The $P$ value of less than 0.05 was considered significant.

The research protocol was approved by the Research Ethics Committee of Shahid Sadoughi University of Medical Sciences (code: IR.SSU.SPH.REC.1396.162 dated 17/2/2018). In addition, after explaining the research purposes to the menopausal women in person, a written informed consent was obtained to ensure confidentiality of information and voluntarily participation. The questionnaire was completed by the researcher.

\section{RESULTS}

The mean $\pm(S D)$ age of women in this study was $48.75 \pm$ $(S D=1.7)$ year with $46.2 \%$ of women had level of education below a diploma, $56.7 \%$ were housewives, and $40.1 \%$ had a monthly income level of 4 Million or more. Subject's demographic characteristics are reported in Table 1.

The mean score of menopausal symptoms severity was $10.21(S D=6.50)$ while the mean score of the subjects' lifestyle was $126.44(\mathrm{SD}=27.8)$ (Table $\mathbf{1})$.

The results of Pearson correlation test showed a significant relationship between severity of menopause symptoms and lifestyle score, number of deliveries, marriage age, number of children, and menopause age $(P<0.001)$. The results of one-way ANOVA showed a statistically significant difference between the mean score of menopausal symptoms severity in different levels of education and income $(P<0.001)$ (Table 2$)$.

The results of hierarchical multiple linear regression models showed (crude and adjusted models) a negative significant relationship between lifestyle and severity of menopause symptoms (Table 3 ). 
Table 1. Distribution of Socio-demographic Variables of the Participant $(n=312)$

\begin{tabular}{|c|c|c|}
\hline Variables & Categories & Mean (SD) or $n(\%)$ \\
\hline Age & - & $48.75(1.7)$ \\
\hline Number of children & - & $3.31(1.3)$ \\
\hline Menopause age & & $46.39(1.47)$ \\
\hline Number of deliveries & - & $3.54(1.5)$ \\
\hline Marriage age & - & $19.91(4.0)$ \\
\hline Total mean score of the severity of menopausal symptoms & - & $10.21(6.6)$ \\
\hline Total mean score of the lifestyle & - & $126.44(27.8)$ \\
\hline \multirow{5}{*}{ Education level } & Under diploma & $144(46.2 \%)$ \\
\hline & Associate degree & $28(9.0 \%)$ \\
\hline & Bachelor's degree & $82(26.3 \%)$ \\
\hline & Masters' degree & $36(11.5 \%)$ \\
\hline & PhD degree & $22(7.1 \%)$ \\
\hline \multirow{2}{*}{ Occupation } & Housewife & $177(56.7 \%)$ \\
\hline & Employee & $135(43.3 \%)$ \\
\hline \multirow{5}{*}{ Household income level } & $\begin{array}{c}\text { Under } 100 \$ \\
\left(<1 \text { millionTomans }{ }^{\star}\right.\end{array}$ & $5(1.6 \%)$ \\
\hline & $\begin{array}{c}\text { Between 100-200\$ } \\
\left(1-2 \text { millionTomans }{ }^{\star}\right)\end{array}$ & $16(5.1 \%)$ \\
\hline & $\begin{array}{c}\text { Between } 200-300 \$ \\
\left(2-3 \text { million Tomans }{ }^{\star}\right)\end{array}$ & $65(20.8 \%)$ \\
\hline & $\begin{array}{c}\text { Between300-400\$ } \\
\left(3-4 \text { million Tomans }{ }^{\star}\right)\end{array}$ & $101(32.4 \%)$ \\
\hline & $\begin{array}{c}\text { More than } 400 \$ \\
\left(>4 \text { million Tomans }{ }^{\star}\right)\end{array}$ & $125(40.1 \%)$ \\
\hline \multirow{5}{*}{ Menopause duration } & 1 year & $110(35.3 \%)$ \\
\hline & 2 years & $82(26.3 \%)$ \\
\hline & 3 years & $52(16.7 \%)$ \\
\hline & 4 years & $42(13.5 \%)$ \\
\hline & 5 years & $26(8.4 \%)$ \\
\hline \multirow{2}{*}{ Housing } & Owner & $263(84.3 \%)$ \\
\hline & Rented & $49(15.7 \%)$ \\
\hline
\end{tabular}

${ }^{*}$ Million Tomans is the Iranian currency

Table 2. The Bivariate Analysis of Independent Variables, Lifestyle and Menopause Severity ( $N=312)$

\begin{tabular}{|c|c|c|c|c|}
\hline Independent variable & Categories & Type of test & Pearson Correlation & P-value \\
\hline Age & - & Correlation & .107 & .06 \\
\hline Menopause duration & & Correlation & -.116 & $\mathrm{P}<0.001$ \\
\hline Menopause age & & Correlation & -.207 & $\mathrm{P}<0.01$ \\
\hline Number of deliveries & - & Correlation & -.501 & $\mathrm{P}<0.001$ \\
\hline Marriage age & - & Correlation & .684 & $\mathrm{P}<0.001$ \\
\hline Number of children & - & Correlation & -.516 & $\mathrm{P}<0.001$ \\
\hline Life Style & - & Correlation & -.781 & $\mathrm{P}<0.001$ \\
\hline \multirow{5}{*}{ Education level } & Under diploma & \multirow{5}{*}{ ANOVA } & \multirow{5}{*}{ - } & \multirow{5}{*}{$\mathrm{P}<0.001$} \\
\hline & Associate degree & & & \\
\hline & Bachelor's degree & & & \\
\hline & Masters' degree & & & \\
\hline & PhD degree & & & \\
\hline \multirow{2}{*}{ Job } & Housewife & \multirow{2}{*}{ T-test } & \multirow[b]{2}{*}{ - } & \multirow{2}{*}{$P<0.001$} \\
\hline & Employee & & & \\
\hline \multirow[t]{2}{*}{ Ownership of house } & Personal & \multirow{2}{*}{ T-test } & \multirow[b]{2}{*}{-} & \multirow{2}{*}{$P<0.05$} \\
\hline & Rented & & & \\
\hline \multirow{5}{*}{ Income } & Between 100-200\$ (1-2 million Tomans) & \multirow{5}{*}{ ANOVA } & \multirow{5}{*}{ - } & \multirow{5}{*}{$P<0.001$} \\
\hline & Between 200-300\$ (2-3 million) & & & \\
\hline & Between $300-400 \$$ (3-4 million) & & & \\
\hline & More than $400 \$$ (>4 million) & & & \\
\hline & Between 100-200\$ (1-2 million Tomans) & & & \\
\hline
\end{tabular}


Table 3. The Results of hierarchical multiple regression Models

\begin{tabular}{|c|c|c|c|c|c|c|c|c|c|c|c|c|c|}
\hline & & \multicolumn{4}{|c|}{ Model 1} & \multicolumn{4}{|c|}{ Model 2} & \multicolumn{4}{|c|}{ Model 3} \\
\hline \multicolumn{2}{|c|}{ Independent variables } & \multicolumn{2}{|c|}{$\begin{array}{l}\text { Coefficients } \\
\text { (SE) }\end{array}$} & \multirow{2}{*}{$\begin{array}{c}\text { Beta } \\
\begin{array}{c}\text { (Standardized } \\
\text { Coefficients) }\end{array} \\
-.781 \\
\end{array}$} & \multirow{2}{*}{$\begin{array}{c}\begin{array}{c}\text { p- } \\
\text { value }\end{array} \\
.0001 \\
\end{array}$} & \multicolumn{2}{|c|}{$\begin{array}{l}\text { Coefficients } \\
\text { (SE) }\end{array}$} & \multirow{2}{*}{$\begin{array}{c}\text { Beta } \\
\text { (Standardized } \\
\text { Coefficients) } \\
-.647 \\
\end{array}$} & \multirow{2}{*}{$\begin{array}{c}\begin{array}{c}\text { p- } \\
\text { value }\end{array} \\
.0001 \\
\end{array}$} & \multicolumn{2}{|c|}{$\begin{array}{l}\text { Coefficients } \\
\text { (SE) }\end{array}$} & \multirow{2}{*}{$\begin{array}{c}\text { Beta } \\
\text { (Standardized } \\
\text { Coefficients) } \\
-.708 \\
\end{array}$} & \multirow{2}{*}{$\begin{array}{c}\begin{array}{c}\text { p- } \\
\text { value }\end{array} \\
.0001\end{array}$} \\
\hline Lifes & style score & -.184 & .008 & & & -.152 & .012 & & & -.167 & .011 & & \\
\hline & Age & - & - & - & - & .331 & .123 & .086 & .007 & 1.397 & 1.696 & .361 & .411 \\
\hline & Job & - & - & - & - & 1.190 & .926 & .090 & .199 & .486 & .867 & .037 & .576 \\
\hline Owners & ship of house & - & - & - & - & 1.374 & .510 & .076 & .007 & .966 & .474 & .054 & .043 \\
\hline \multirow{5}{*}{$\begin{array}{l}\text { Income } \\
\text { level }\end{array}$} & $\begin{array}{c}\text { Between 100- } \\
200 \$(1-2 \\
\text { millionTomans) }\end{array}$ & - & - & - & - & - & - & - & - & - & - & - & - \\
\hline & $\begin{array}{c}\text { Between 200- } \\
300 \$(2-3 \text { million) }\end{array}$ & - & - & - & - & -12.292 & 1.624 & -.414 & .0001 & -14.948 & 1.997 & -.504 & .0001 \\
\hline & $\begin{array}{c}\text { Between300- } \\
400 \$(3-4 \text { million) } \\
\end{array}$ & - & - & - & - & -14.519 & 1.511 & -.901 & .0001 & -17.212 & 1.947 & -1.068 & .0001 \\
\hline & $\begin{array}{c}\text { More than } 400 \$ \\
(>4 \text { million })\end{array}$ & - & - & - & - & -15.661 & 1.486 & -1.120 & .0001 & -19.146 & 1.943 & -1.369 & .0001 \\
\hline & $\begin{array}{c}\text { Between 100- } \\
200 \$(1-2 \\
\text { millionTomans) }\end{array}$ & - & - & - & - & -16.276 & 1.541 & -1.219 & .0001 & -19.109 & 1.986 & -1.431 & .0001 \\
\hline \multirow{5}{*}{$\begin{array}{l}\text { Education } \\
\text { Level }\end{array}$} & Under diploma & - & - & - & - & - & - & - & - & - & - & - & - \\
\hline & Associate degree & - & - & - & - & -2.908 & .673 & -.127 & .000 & -3.058 & .631 & -.134 & .000 \\
\hline & $\begin{array}{c}\text { Bachelor's } \\
\text { degree }\end{array}$ & - & - & - & - & -2.265 & 1.074 & -.152 & .036 & -1.817 & 1.006 & -.122 & .072 \\
\hline & Masters' degree & - & - & - & - & -3.571 & 1.243 & -.174 & .004 & -3.940 & 1.184 & -.192 & .001 \\
\hline & PhD degree & - & - & - & - & -2.371 & 1.281 & -.093 & .065 & -1.731 & 1.276 & -.068 & .176 \\
\hline \multicolumn{2}{|c|}{ Menopause duration } & - & - & - & - & - & - & - & - & -.530 & 1.694 & -.115 & .755 \\
\hline \multicolumn{2}{|c|}{ Menopause age } & - & - & - & - & - & - & - & - & -1.586 & 1.691 & -.356 & .349 \\
\hline \multicolumn{2}{|c|}{ Delivery } & - & - & - & - & - & - & - & - & -.837 & .392 & -.191 & .033 \\
\hline \multicolumn{2}{|c|}{ Marriage age } & - & - & - & - & - & - & - & - & .234 & .082 & .144 & .005 \\
\hline \multicolumn{2}{|c|}{ Number of children } & - & - & - & - & - & - & - & - & .748 & .413 & .150 & .071 \\
\hline \multicolumn{2}{|r|}{$N$} & \multicolumn{4}{|c|}{312} & \multicolumn{4}{|c|}{312} & \multicolumn{4}{|c|}{312} \\
\hline
\end{tabular}

\section{DISCUSSION}

Our study found a significant relationship between lifestyle factors and the severity of menopausal symptoms; where those with a healthier lifestyle had less severity of menopausal symptoms. This finding contradicts findings by Guimaraz et al. (2010) that physical activity had no significant effect on menopausal symptoms (22). In a study by Bahriand colleagues (2013), there was no significant relationship between the severity of menopausal symptoms with anxiety and depression (23), which is also inconsistent with the results of the present study, possibly due to the difference in the measurement scale of menopausal symptoms. On the other hand, a study by Lopez et al. (2011) showed a significant relationship between lifestyle dimensions, physical activity, interpersonal relationships and spiritual growth with the number and severity of hot flashes and the number and severity of nightly sweating (24), which is partly in line with the results of our study. Furthermore, an earlier work by Ivarsson et al. (1998) found that by increasing physical activity, the severity of hot flashes reduced (25).

In the present study, there was a significant relationship between type of housing, occupation, age of marriage, menopausal age and menopausal duration and the severity of menopausal symptoms. In the study of Chedraui et al. age, menopause age, sexual inactivity and educational level were found to be independent risk factors predicting more severe menopausal symptoms. Women with lower educational level presented higher somatic and psychological scorings in comparison to their counterparts (5). Gold et al. in a crosssectional study found age to be significantly associated with vasomotor symptoms, although a dose-response relation with hours of smoke exposure was not observed. No dietary nutrients were significantly associated with vasomotor symptoms (26). In the study of Ghorbani (16), a significant relationship between the number of pregnancies and the number of children and the severity and duration of hot flashes was found, which was not consistent with the results of the present study. The results of this study showed that, the longer the age of menopause the more severe the symptoms of menopause. Moreover, we found the severity of menopausal symptoms to be positively associated with the number of deliveries and the number of children. In the present study, there was a significant reverse relationship between the marriage age and the severity of menopausal symptoms; where those who had a higher marriage age reported less severity of menopausal symptoms. This could be due to the fact that those who are married at an early age are more likely to be involved in life events and have more life-threatening conditions that can increase the severity of menopausal symptoms. Furthermore, in the present study, the severity of menopausal symptoms varied in different levels of education. Those with higher levels of education had less severity of menopausal symptoms. Gold et al. (2004) also found a significant relationship between the individuals' level of education and the severity of hot flashes and nightly sweating (26), which is consistent with the results of the present study. Moreover, the study of Ayati et al. indicated that within creasing the level of education, fewer individuals experienced hot flashes (27), which is also in line with our findings. This could be explained by the fact that those with higher levels of education have better awareness and subsequently better strategies to cope with menopausal symptoms, and, they are more likely to be health conscious and therefore seek health 
advice. In addition, no physically active women, overweight, excessive alcohol use could reported higher somatic symptoms than did women with a sedentary lifestyle (20).

In the present study, there was a significant inverse relationship between the healthy lifestyle and menopause duration.

\section{CONCLUSIONS}

Our cross-sectional analysis revealed a significant relationship between severity of menopausal symptoms and lifestyle factors. This is a significant public health issue and should be considered in the design of healthcare programs and plans to prevent and reduce menopausal symptoms and reduce and alleviate the burden associated with the inevitable menopause. Basic lifestyle modification, including regular physical activity, having healthy nutrition and avoiding tobacco smoking may play an important role in reducing the severity of menopausal symptoms. Policy makers and health professionals should pay special attention to promote the healthy lifestyle in developing preventive and care programs for postmenopausal women. Longitudinal studies are required to confirm these cross-sectional findings.

\section{ACKNOWLEDGEMENTS}

Hereby, we gratefully thank the menopause women who helped us conduct this work, also social determinants of health research center for financial support of the project, and the deputy of health and the staff of the health centers who helped the researchers in conducting this project.

\section{REFERENCES}

1. Ceylan B, Özerdoğan N. Menopausal symptoms and quality of life in Turkish women in the climacteric period. Climacteric. 2014;17(6):705-12. https://doi.org/10.3109/ 13697137.2014.929108 PMid:24884351

2. Im E-O, Young K, Chee E, Chee W. A cluster analysis on midlife women's sleep-related symptoms: racial/ethnic differences. Menopause (New York, NY). 2015;22(11):1182. https://doi.org/10.1097/GME.0000000000000460 PMid:25871005 PMCid:PMC4866935

3. Pachana NA, Helmes E, Gudgeon S. An A ustralian facts on ageing quiz. Australasian journal on ageing. 2013;32(2):11721. https://doi.org/10.1111/j.1741-6612.2012.00635.x PMid:23773252

4. sco I. Statistical Yearbook country. 2015.

5. Chedraui $P$, Blümel JE, Baron G, Belzares E, Bencosme A, Calle $A$, et al. Impaired quality of life among middle aged women: a multicentre Latin American study. Maturitas. 2008;61(4):323-9. https://doi.org/10.1016/j.maturitas.2008. 09.026 PMid: 19010618

6. Lu J, Liu J, Eden J. The experience of menopausal symptoms by Arabic women in Sydney. Climacteric. 2007;10(1):72-9. https://doi.org/10.1080/136971306011596 49 PMid: 17364607
7. Peeyananjarassri K, Cheewadhanaraks S, Hubbard M, Zoa Manga R, Manocha R, Eden J. Menopausal symptoms in a hospital-based sample of women in southern Thailand. Climacteric. 2006;9(1):23-9. https://doi.org/10.1080/ 13697130500487422 PMid:16428122

8. Olajubu A, Olowokere A, Amujo D, Olajubu T. Influence of menopausal symptoms on perceived work ability among women in a Nigerian University. Climacteric. 2017;20(6):558-63. https://doi.org/10.1080/13697137.2017. 1373336 PMid:28933968

9. Heydari L, Suhrabi Z, Sayehmiri F, Sayehmiri K. Effect of herbaceous medicines effective in hot flashes of menopause women: a systematic review and metaanalysis in Iran. The Iranian Journal of Obstetrics, Gynecology and Infertility. 2014;17(109):16-25.

10. Yoosefzadeh S. Nutrition, Lifestyle and Exercise in Menopausal Women in Sabzevar, Iran Journal of Sabzevar University of Medical Sciences. 2004;11(1):62-6.

11. Kim H. Soy may reduce of alzheimer after menopause. Warner Books. Avaiable from: http://www. Menopause. org $\mathrm{Html} ; 2003$.

12. Naghibi F, Golmakani N, Esmaily H, Moharari F. The relationship between life style and the health related quality of life among the girl students of high schools in Mashhad, 2012-2013. The Iranian Journal of Obstetrics, Gynecology and Infertility. 2013;16(61):9-19.

13. Amiri A, Rkhshany F, Farmanbar R. The effect of educational program based on BASNEF model on healthy lifestyle of taxi drivers in Langroud. Journal of Torbat Heydariyeh University of Medical Sciences. 2014;1(4):45-54.

14. Sima Ghezelbash, Ghorbani A. Lifestyle modification and hypertension prevention ARYA Atherosclerosis Journal. 2012;8(Special Issue in National Hypertension Treatment):6-1.

15. Babaei-Sis M, Ranjbaran S, Mahmoodi H, Babazadeh $T$, Moradi F, Mirzaeian K. The Effect of Educational Intervention of Life Style Modification on Blood Pressure Control in Patients with Hypertension. J Educ Community Health. 2016;3(1):12-9. https://doi.org/10.21859/jech03012

16. Ghorbani M, Azhari S, Esmaili H, Ghanbari Hashemabadi B. The Relationship between Life Style with Vasomotor Symptoms in Postmenopausal Women Referred to Women's Training Health Centers in Mashhad in 2011. The Iranian Journal of Obstetrics, Gynecology and Infertility. 2013;15(39):23-30.

17. Azhari S, Ghorbani M, Esmaeili H. Evaluation of the relationship between lifestyle and quality of sleep in postmenopausal women. The Iranian Journal of Obstetrics, Gynecology and Infertility. 2014;17(112):7-14.

18. Tartibian B, Sharabiani S, Abbasi A. Effect of regular aerobic exercise on vasomotor symptoms (hot flashes) in postmenopausal women. 2009.

19. Blümel JE, Fica J, Chedraui P, Mezones-Holguín E, Zuñiga MC, Witis S, et al. Sedentary lifestyle in middle-aged women is associated with severe menopausal symptoms and obesity. Menopause. 2016;23(5):488-93. https://doi.org/ 10.1097/GME.0000000000000575 PMid:26818013

20. Moilanen J, Aalto A-M, Hemminki E, Aro AR, Raitanen J, Luoto R. Prevalence of menopause symptoms and their association with lifestyle among Finnish middle-aged women. Maturitas. 2010;67(4):368-74. https://doi.org/ 10.1016/j.maturitas.2010.08.007 PMid:20869181 
21. Ahmadi A, Roosta F. Health knowledge and health promoting lifestyle among women of childbearing age in Shiraz. Women's Health Bulletin. 2015;2(3). https://doi.org/10.17795/whb-25342

22. de Azevedo Guimarães AC, Baptista F. Influence of habitual physical activity on the symptoms of climacterium/menopause and the quality of life of middleaged women. International journal of women's health. 2011;3:319. https://doi.org/10.2147/IJWH.S24822 PMid:22114524 PMCid:PMC3220314

23. Bahri N, Afiat M, Aghamohamadian HR, Delshad Noughabi A, Bahri N. Investigating the relationship between severity of menopausal symptoms and depression, anxiety and other menopausal symptoms. The Iranian Journal of Obstetrics, Gynecology and Infertility. 2013;16(43):14-20.

24. López-Alegría F, De DL. Lifestyles and quality of life of post menopausal women. Revista medica de Chile. 2011;139(5):618-24. https://doi.org/10.4067/S0034-988720 11000500009 PMid:22051713
25. Ivarsson T, Spetz A-C, Hammar M. Physical exercise and vasomotor symptoms in postmenopausal women. Maturitas. 1998;29(2):139-46. https://doi.org/10.1016/ S0378-5122(98)00004-8

26. Gold EB, Block G, Crawford S, Lachance L, FitzGerald G, Miracle $\mathrm{H}$, et al. Lifestyle and demographic factors in relation to vasomotor symptoms: baseline results from the Study of Women's Health Across the Nation. American journal of epidemiology. 2004;159(12):1189-99. https://doi.org/10.1093/aje/kwh168 PMid:15191936

27. Ayati C, Kadkhodaeian S, Rood Sari F, Shakeri M. Examine the relationship between environmental factors and the symptoms of menopause. J Babol Univ Med Sci. 2009;1:405. 